\title{
COL3A1 Gen Polymorphism in Women with Pelvic Floor Dysfunctions: A Case Control Study
}

\author{
Vishnevskiy DA*2, Kasyan GR², Akulenko LV' ${ }^{1}$, Kozlova YO ${ }^{1}$, Tupikina $\mathrm{NV}^{2}$ and Pushkar DY2 \\ ${ }^{1}$ Department of Genetics, Moscow State University of Medicine and Dentistry named after Evdokimov AI at Ministry of Health of the Russian Federation, Russia \\ ${ }^{2}$ Department of Urology, Moscow State University of Medicine and Dentistry named after Docomo A. I. at Ministry of Health of the Russian Federation, Russia
} Received: 阱 July 27, 2018; Published: 阱 August 09, 2018

*Corresponding author: Vishnevsky DA, Department of Urology at Moscow State University of Medicine and Dentistry named after A.I. Evdokimov, Russia

Abbreviations: POP: Pelvic Organs; SUI: Stress Urinary Incontinence; G: Guanine; A: Adenine

\section{Introduction}

Pelvic floor dysfunction is a complex of disorders of the fascial structures and pelvic floor muscles that keep the pelvic organs in a normal position and provide continence of urine and feces [1-6]. The POP amounts $30.8 \%$ in the structure of urogynecological pathology in European countries [7], in the Middle East countries - 19.9-49.6\% [4], in the countries of North and East Africa - 46-56\% [8]. In recent years, the incidence of POP has been increasing worldwide [9]. However, despite the growing prevalence of pelvic floor dysfunction in women, there is no consensus on its etiology and pathogenesis to date. Herewith, there is no doubt that this is a multifactorial pathology, the development of which is determined by genetic and environmental factors. The environmental factors contributing to the development of pelvic floor dysfunction in women have been studied quite well. Those include traumatic and prolonged labor, estrogen deficient conditions, diseases accompanied with increased intra-abdominal pressure (bronchitis, bronchial asthma, constipation, etc.), disturbance of microcirculation of blood and lymph in the small pelvis, obesity, and sedentary lifestyle $[5,10,11]$.

As for genetic factors, already at the beginning of the 20th century it was known about existence of family cases of POP. This fact served as the basis for conducting large-scale studies using classical methods of genetic analysis - clinical-genealogical, population-statistical and twin studies, aimed to elucidate the role of hereditary factors in the development of pelvic floor dysfunction in women. The generalized results of these studies have convincingly demonstrated that in families of probands (patients) a pelvic floor dysfunction occurs 3-5 times more often than it would be expected based on the frequency of this pathology in population. It was shown that for healthy relatives of a proband of 1 degree of kinship (mothers, sisters, daughters), the risk of developing of a similar pathology was increased 5 -fold, compared to risk in general population [12]. A formal-genetic analysis performed on the material of the Swedish and Danish twin registers showed that the correlative contribution of hereditary and environmental factors to the predisposition to POP is $43 \%$ and $57 \%$, respectively [2]. It was found that in the general structure of POP the family forms (2 or more cases among relatives of 1 degree of kinship) make up $28 \%$ and that in such families the disease is inherited by an autosomal dominant type with high penetrance $[12,13]$.

Therefore, genetic- epidemiological studies have justified the appropriateness for searching the specific molecular-genetic factors that form the structure of hereditary predisposition to pelvic floor dysfunction in women. The international gene disease database (Huge Navigator) contains about 30 publications on the exploration for genetic factors associated with pelvic floor dysfunction in women. Most of the works are devoted to the studying of genes controlling the synthesis and degradation of connective tissue, and particularly to collagen genes (COL1A1, COL3A1), matrix metalloproteinases 1, 3, 9 (MMP1, MMP3, MMP9) and laminin (LAMC1) (http://www.cdc.gov/genomics/hugenet/hugenavigator. htm). As early as in 1966, a hypothesis was stated about the role of disturbance of collagen metabolism in the development of POP, which was based on data on reduced content of total collagen by $25 \%$ in vaginal epithelial tissue in women with POP compared with healthy women [14].

For support of pelvic organs, the most important are collagen types I and III. The binding apparatus is mostly of type I collagen, giving strength to the ligaments due to the length and thickness of the fibers, and less- type III collagen, increased amount of which is associated with a decrease in the mechanical strength of the connective tissue. The role of polymorphism of the COL3A1 gene remains controversial. Some studies and meta-analysis found a 
strict correlation between these genetic defects and POP, other investigators did not confirm it $[3,15]$. The aim of our study is to clarify the place of polymorphism of the COL3A1 gene in the development of POP and urinary incontinence.

\section{Materials and Methods}

The study involved 250 women. All these women underwent treatment in the University urology department from September 2016 to June 2017. These women were divided into a control and research groups. The study group included 150 patients with prolapse of pelvic organs (POP) and stress urinary incontinence (SUI). Patients between the ages of 40 years and 70years were included (average 64.4years). Inclusion criteria's a study and control groups were limited to having at least one or more risk factors, such as: two or more births through natural paths, traumatic births, births of more than 4,000 grams, excessive physical activity, diseases accompanied by increased intra-abdominal pressure (bronchial asthma, chronic bronchitis, chronic constipation), history of pelvic surgery. The control group included 100 patients without POP and SUI, matched with age and risk factors. These patients were admitted in a urological department for other reasons. Patients between the ages of 40years and 70years were included (average 63.2years). All patients have at least 1 of the realized risk factors as in the study group. In both groups, saliva samples were taken for genetic analysis. Saliva samples were collected from all patients for detection of rs1800255 polymorphism of the COl3A1 gene. This polymorphism is a local mutation, which results in substitution of guanine $(G)$ for adenine (A) in DNA sequence. Genotyping was performed by Sanger sequencing method, followed by estimation of sensitivity and specificity for POP and SUI.

\section{The Mechanism of Genetic Material Intake}

An hour before the saliva was given the patient should not eat, drink or smoke. To collect saliva was used a sterile plastic tube. Before giving the saliva, the patients chewed the cheeks mucous during several seconds. Then spit into a test tube $3-4 \mathrm{ml}$ of saliva. On the test tube was written the individual number of the patient. And it was placed in the freezer. As the material accumulated, the material was sent to the laboratory.

\section{Sequencing in Laboratory}

Saliva samples were collected from all patients for detection of rs1800255 polymorphism of the COl3A1 gene. This polymorphism is a point mutation which results in substitution of guanine $(G)$ for adenine (A) in DNA sequence. Genotyping was performed by Sanger sequencing method, followed by estimation of sensitivity and specificity for POP and SUI. For SNP detection we design two primers $\sim 200-350$ bp upstream and $\sim 200-350$ bp downstream of needed position to amplify a $400-700 \mathrm{bp}$ fragment. Primers specificity was confirmed by PCR with subsequent electrophoresis in agarose gel. Sanger sequence of PCR product was performed on ABI 3730XL (Life Technologies) from one end, one reaction per template on ABI. Final primers were.

\section{a) f primer TAGTTCCCACCCAGCTGTTC \\ b) $\mathrm{r}$ primer ACCTTGTCACCCTTTGGACC}

\section{Statistical Analysis}

The genotyping data were subjected to statistical processing using the PASW Statistics program 22. The descriptive statistics were presented as the mean and standard deviation, the median and the 25 th and 75 th percentile, the minimum and maximum values in the sample for the quantitative variables, as well as the frequencies of occurrence and shares in the sample for qualitative variables. To compare the quantitative data in two unrelated samples, the MannWhitney U test was applied. To compare the nominal variables in two unrelated sets, Fisher's exact test was used. The significance level (p) was assumed to be 0.05 in all comparisons.

\section{Results}

The study involved 250 patients who received treatment at the urology clinics of the Moscow State Medical University. 150 patients with POP and / or SUI were included in the study group. These patients between the ages of 40 to 70 years (mean age 64,4 \pm 2 years) had at least one external risk factor (two or more births through natural birthmarks, traumatic births, births of more than $4,000 \mathrm{~g}$, excessive physical activity, accompanied by an increase in abdominal pressure (bronchial asthma, chronic bronchitis, chronic constipation), the presence of operations on the pelvic organs). The control group included 100 patients, without pelvic floor dysfunction, between the ages 40 to 70 years (mean age 63.2 \pm 2 years). These patients had the same external risk factors as the study group patients. All the genetic variants studied within the framework of the present work were in a state of equilibrium in the Hardy-Weinberg sense. The results of genotyping for the polymorphism rs1800255 in the COL3A1 gene are reflected in Table 1. Genotyping data were subjected to statistical analysis. Statistical analysis didn't reveal differences between the study group and the control group.

Table 1: Results of genotyping polymorphism rs1800255 in the gene COL3A1.

\begin{tabular}{|c|c|c|c|}
\hline \multirow{2}{*}{ Groups } & \multicolumn{3}{|c|}{ Genotype } \\
\cline { 2 - 4 } & GG & GA & AA \\
\hline Study group & $90(60 \%)$ & $50(33,3 \%)$ & $10(6,7 \%)$ \\
\hline Control group & $64(64 \%)$ & $28(28,0 \%)$ & $8(8,0 \%)$ \\
\hline
\end{tabular}

\section{Discussions}

The authors showed that the development of POP is associated not with this polymorphic variant, but with the carrier of the genotype rs1800255-A/A of the COL3A1 gene, which increases the probability of the development of POP in 4.79 times. According to the authors, the nucleotide substitution of 2092G>A (rs1800255) leads to the replacement of alanine with threonine (Ala698Thr), which may affect the strength of collagen fibers [15]. Another meta-analysis performed in 2015 by Cartwright and co-authors did not confirm the association of the rs1800255-A/A gene of COL3A1 with the development of POP but confirmed the correlation of the polymorphic variant rs1800012 of the COL1A1 gene with the risk of developing POP [3]. Summarizing the analysis of world literature, it should be noted that classical genetic-epidemiological studies have provided evidence that pelvic floor dysfunction in women is 
a pathology with hereditary predisposition, the development of which is determined by the interaction of multiple additive genetic factors (mutations and / or polymorphic alleles) and environmental factors.

The present study was carried out in order to elucidate the relationship between POP and SUI with the carrier of polymorphisms rs1800255 in the gene COL3A1 by genotyping the saliva samples of the patients of the analytical and control group by the Sanger sequencing method. Sequencing by Sanger is currently the gold standard in the genotyping of single polymorphisms, so this is the method chosen for this study. The genotyping of the patients in the study group (150 people) and the control group (100 people) and the subsequent statistical analysis didn't reveal the association of rs1800255 polymorphisms in the gene COL3A1 with pelvic floor dysfunction.

\section{Conclusion}

Thus polymorphisms rs1800255 in the gene COL3A1 don't participate in the formation of a predisposition to POP and SUI. Further studies of these polymorphisms don't seem appropriate.

\section{References}

1. Adjoussou SA, Bohoussou E, Bastide S, Letouzey V, Fatton B, et al. (2014) Functional symptoms and associations of women with genital prolapse. Prog Urol 24(8): 511-517.

2. Altman D, Forsman M, Falconer C, Lichtenstein P (I2008) Genetic influence on stress urinary incontinence and pelvic organ prolapse. Eur Urol 54(4): 918-922.

3. Cartwright R, Kirby AC, Tikkinen KA, Mangera A, Thiagamoorthy G, et al. (2015) Systematic review and meta-analysis of genetic association studies of urinary symptoms and prolapse in women. Am J Obstet Gynecol 212(2): 199 e1-199 e24.

4. Deeb ME, Awwad J, Yeretzian JS, Kaspar HG (2003) Prevalence of reproductive tract infections, genital prolapse, and obesity in a rural community in Lebanon. Bull World Health Organ 81(9): 639-645.
5. Dubowitch E, Cahn D, Ross C, Husain A, Harkaway R, et al. (2014) Procidentia as a cause of obstructive uropathy and acute kidney injury. Curr Urol 7(4): 207-209.

6. Dviri M, Leron E, Dreiher J, Mazor M, Shaco Levy R (2011) Increased matrix metalloproteinases-1,-9 in the uterosacral ligaments and vaginal tissue from women with pelvic organ prolapse. Eur J Obstet Gynecol Reprod Biol 156(1): 113-117.

7. Samuelsson EC, Victor FT, Tibblin G, Svardsudd KF (1999) Signs of genital prolapse in a Swedish population of women 20 to 59 years of age and possible related factors. Am. J. Obstet. Gynecol 180(2 Pt l): 299305.

8. Tegerstedt G, Maehle Schmidt M, Nyrén O, Hammarström M (2005) Prevalence of symptomatic pelvic organ prolapse in a Swedish population. Int Urogynecol J Pelvic Floor Dysfunct 16(6): 497-503.

9. Schaffer JI, Bloom SL, Casey BM, McIntire DD, Nihira, et al. (2005) A randomized trial of the effects of coached vs uncoached maternal pushing during the second stage of labor on postpartum pelvic floor structure and function. Am J Obstet Gynecol 192(5): 1692-1696.

10. Haim Krissi, Reuvit Halperin, Pumella Koren, Yoav Peled (2010) The presence and location of estrogen and progesterone receptors in the human pelvic cardinal ligaments. Pelviperineology 29: 17-19.

11. Lowder JL, Frankman EA, Ghetti C, Burrows LJ, Krohn MA, et al. (2010) Lower urinary tract symptoms in women with pelvic organ prolapse. Int Urogynecol J 21(6): 665-672.

12. Mothes AR, Radosa MP, Altendorf Hofmann A, Runnebaum IB (2016) Risk index for pelvic organ prolapse based on established individual risk factors. Arch Gynecol Obstet 293(3): 617-624.

13. Lince SL, van Kempen LC, Vierhout ME, Kluivers KB (2012) A systematic review of clinical studies on hereditary factors in pelvic organ prolapse. Int Urogynecol J 23(10): 1327-1336.

14. Tegerstedt G, Maehle Schmidt M, Nyrén O, Hammarström M (2005) Prevalence of symptomatic pelvic organ prolapse in a Swedish population. Int Urogynecol J Pelvic Floor Dysfunct 16(6): 497-503.

15. Ward RM, Velez Edwards DR, Edwards T, Giri A, Jerome RN, et al. (2014) Genetic epidemiology of pelvic organ prolapse: a systematic review. Am J Obstet Gynecol 211(4): 326-335.

16. http:.www.cdc.gov/genomics/hugenet/hugenavigator.htm
ISSN: 2574-1241

DOI: $10.26717 / B J S T R .2018 .07 .001557$

Vishnevsky DA. Biomed J Sci \& Tech Res

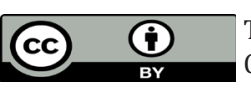

This work is licensed under Creative Commons Attribution 4.0 License

Submission Link: https://biomedres.us/submit-manuscript.php

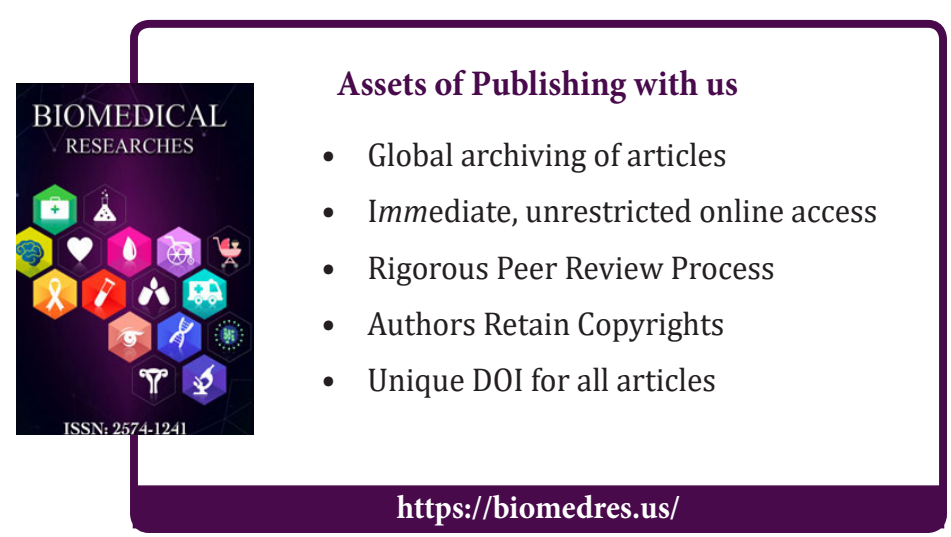

